Auszug aus einem Schreiben des Herrn Hofraths und 3itters Gauss an den Herausgeber. 1827. Oct. 11.

Hier meine bísherigen Somnenzenithdistanzen, die nur von der Refraction befreiet sind. In der folgenden Columne steht die Parallaxe (sie ist für das Centrum berechnet, oder vielmehr aus der ausgefiillten Columne Hülfstafeln 1821 entlehnt; es ist genauer sie für den beobachteten Rand zu nehmen, der Unter-

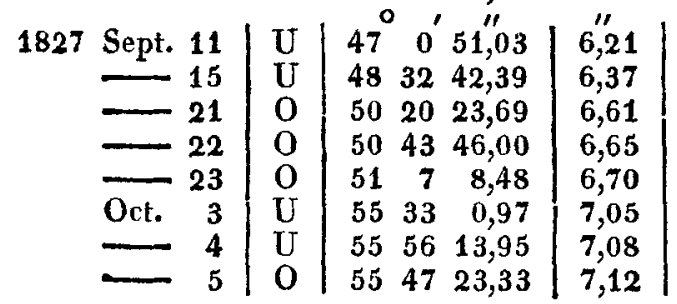

Die $0^{\prime \prime}, 77$, um welche ich den Sonnenhalbmesser vermindern mufs, können vielleicht zum Theile davon abhängen, dafs bei dem Urtheil über die Halbirung des Fadenintervalls, wo die eine Hälfte hell, die andere dunkel ist, etwas individuelles mit unterlaufen mag. schied ist aber nur $\pm 0^{\prime \prime}, 03$ und gleicht sich aus), dann die mit der Polhöhe $51^{\circ} 31^{\prime} 48^{\prime \prime}$, und dem Sonnenhalbmesser aus den Hülfstafeln von 1821 berechnete Declination, dann die Differenz unit den Hülfstafeln, dann die Differenz wenn, wie aus allen sich ergiebt, $d r=-0 ", 77$ gesetut wird.

\title{
Bcobachtungen der Vesta auf der Prager Sternwarte zur Zeit ihres Gegenscheins 1827. Von Professor Bittner.
}

$D_{\text {en } 17,18,19}$ Decenber ward Vesta verglichen mit $2 x$ und $1 \varepsilon$, am 29 Decbr. mit 1 und $4 \chi$ im Orion. Die scheinbaren Orte dieser Sterne waren:

\section{Scheinbare}

Aufsteigung. nördl. Abweichung.
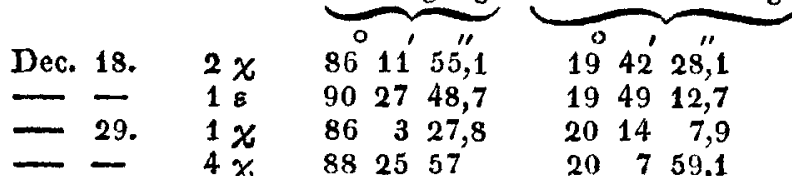

861155,1

$194228, \mathrm{~L}$

$2 x$

$\begin{array}{llll}90 & 27 & 48,7\end{array}$

$1949 \quad 12,7$

$\begin{array}{lll}86 & 3 & 27,8\end{array}$

$\begin{array}{lll}20 & 14 & 7,9\end{array}$

1
4
$x$

$\begin{array}{lll}88 & 25 & 57\end{array}$

$\begin{array}{lll}20 & 7 & 59,1\end{array}$

Prager mittl.

$$
\text { Zeit. }
$$

1827 Dec. 17.

$11^{\mathrm{h}} 56^{\prime} 2^{\prime \prime}$

cheinb. Aufst.

Nördl. A derVesta. $84 \circ 51^{\prime} 25^{\prime \prime}$ weichung. - 18. $1151 \quad 1$

11460 843429,5 $19^{\circ} 46^{\prime} 3^{\prime \prime}$ 19 $10 \quad 55 \quad 49,3$
$1948 \quad 9$

$19 \quad 50 \quad 14$ 201141

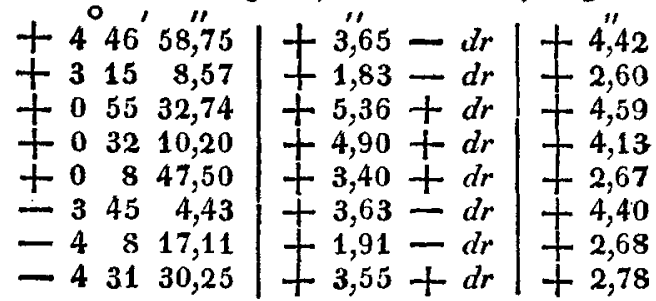

Ich übersende Ihnen ferner hier meine Ceresbeobaclitungen. 1827 Sept. $27 \mid \frac{12}{12} 1 i^{\prime \prime}, 7$ M.z. \begin{tabular}{rr|rrr} 
Oct. & 3 & 11 & 42 & 50,2 \\
- & 4 & 11 & 38 & 3,7 \\
- & 5 & 11 & 33 & 17,7 \\
- & 6 & 11 & 28 & 31,9
\end{tabular}

Nebst diesen besitzt die Prager Sternwarte noch

3. Den 3füfsigen Vollkreis von Troughton, den Herr Ritter Bessel bey seiner Durchreise duren Prag 1827 mit vielem Beyfalle in Augenschein nahm, und sehr bedauerte, dafs an der Sternwarte kein angemessener Ort vorhanden ist, ihn zum Gebrauche fest aufzustellen.

4. Ein' 7 fülsiges Fernrohr mit einem vortrefflichen $\mathrm{Ob}$ jektiv vom alten Dollond, der zuerst achromatische Gläser verfertigte, mit einer parallaktischen Aufstellung.

5. Ein Universalinstrument vom sel. Reichenbach aus Mlünchen.

6. Einen guten 3fülsigen Quadranten von Huberti zu Würzburg, dessen äufseres Schraubenmikrometer einzelne Sekunden angibt.

7. Ein achromatisches Fernrohr vom sel. Fraunhofer gleich dem in der genannten Beschreibung S.14. Nr. XIII.

8. Einen Komelensucher, wie Nr. XIV.

Zur Zeitbestimmung befinden sich auf der Sternwarte sechs astronomische Pendeluhren. Die von Lepaute aus Paris hat der bey der Sternwarte angestellte geschickte Uhrmacher Joseph Kossek durchaus mit Rubinen besetzt.

Da Seine Majestät Kaiser Franz die Prager Sternwarte mit so vortrefflichen Instrumenten ausgerustet haben, hat man Grund zu erwarten, dafs Seine Majestät auch eine $z$ weckmäfsige neue Sternwarte herstellen werden, um diese kostharen Instrumente fest aufzustellen, und zum Nutzen der Wissenschaft zu gebrauchen.

Prag den 27 Mai 1828.

Prof. David, Vorsteher der Prager Sternwarte. 